\title{
Properties of the Cyanobacterial Coupling Factor ATPase from Spirulina platensis
}

\author{
II. Activity of the Purified and Membrane-Bound Enzymes
}

\author{
DAVID B. HICKS ${ }^{1}$ AND CHARLES F. YOCUM
}

Division of Biological Sciences, University of Michigan, Ann Arbor, Michigan 48109-1048

Received August 9, 1985, and in revised form October 24, 1985

Cyanobacterial (Spirulina platensis) photosynthetic membranes and isolated $F_{1}$ ATPase were characterized with respect to ATP activity. The following results indicate that the regulation of expression of ATPase activity in Spirulina platensis is similar to that found in chloroplasts: (a) the ATPase activity of Spirulina membranes and isolated $F_{1}$ ATPase is mostly latent, a characteristic of chloroplast ATPase activity; (b) treatments that elicit ATPase activity in higher plant chloroplast thylakoids and isolated chloroplast coupling factor $\left(\mathrm{CF}_{1}\right)$ greatly stimulate the activity of Spirulina membranes and $\mathrm{F}_{1}$, and (c) the cation specificity of chloroplast ATPase activity, e.g., light-induced membrane activity that is magnesium dependent and trypsin-activated $\mathrm{CF}_{1}$ activity that is calcium dependent, is also observed in Spirulina. Thus, an 8- to 15-fold increase in specific activity (to $13-15 \mu \mathrm{mol} P_{\mathrm{i}} \mathrm{min}^{-1} \mathrm{mg} \mathrm{chl}^{-1}$ ) is obtained when Spirulina membranes are treated with trypsin (CaATPase) or with methanol (MgATPase); a lightinduced, dithiothreitol-dependent MgATPase activity is also found in the membranes. Purified Spirulina $\mathrm{F}_{1}$ is a CaATPase when activated with trypsin (endogenous activity increases from 4 to $27-37 \mu \mathrm{mol} P_{\mathrm{i}} \mathrm{min}^{-1} \mathrm{mg}$ protein $\left.{ }^{-1}\right)$ or with dithiothreitol $(5.6 \mu \mathrm{mol}$ $\left.P_{\mathrm{i}} \min ^{-1} \mathrm{mg}^{-1}\right)$, but a MgATPase when assayed with methanol $\left(18-20 \mu \mathrm{mol} P_{\mathrm{i}} \mathrm{min}^{-1}\right.$ $\mathrm{mg}^{-1}$ ). The effects of varying calcium and ATP concentrations on the kinetics of trypsininduced CaATPase activity of Spirulina $\mathrm{F}_{1}$ were examined. When the calcium concentration is varied at constant ATP concentration, the velocity plot shows a marked sigmoidicity. By varying Ca-ATP metal-nucleotide complex concentration at constant concentrations of free calcium or ATP, it is shown that the sigmoidicity is due to the effect of free ATP, which changes the Hill constant to 1.6 from 1.0 observed when the free calcium concentration is kept constant at $5 \mathrm{mM}$. Therefore not only is ATP an inhibitor but it is also an allosteric effector of Spirulina $F_{1}$ ATPase activity. At $5 \mathrm{~mm}$ free calcium, the $K_{m}$ for the Ca-ATP metal-nucleotide complex is $0.42 \mathrm{mM}$. $\odot 1986$ Academic Press, Inc.

The latent ATPase activity in photosynthetic membranes of oxygen-evolving organisms is strikingly different from the ATPase activity observed in energy-transducing membranes of nonoxygenic photosynthetic and heterotrophic bacteria and mitochondria, which is expressed without

\footnotetext{
${ }^{1}$ Current address: Department of Biochemistry, Mt. Sinai School of Medicine, One Gustave L. Levy Place, New York, N.Y. 10029.
}

treatment. Over two decades ago, Petrack and Lipmann (1) found that ATP hydrolysis in membranes of the cyanobacterium Anabaena variabilis and spinach chloroplasts could be induced by illumination in the presence of an electron transport mediator and a sulfhydryl reagent, and suggested that this activity represented a reversal of ATP synthesis. Since that landmark work, the enzyme that catalyzes ATP hydrolysis in chloroplasts, chloroplast 
coupling factor or $\mathrm{CF}_{1}{ }^{2}$ has been studied in order to understand how its catalytic activity is regulated [reviewed in (2)]. When isolated from the membrane, the latency of $\mathrm{CF}_{1}$ is overcome by dithiothreitol in a reaction that probably mimics the light modulation of membrane-bound $\mathrm{CF}_{1}$ activity (3). However, the cation specificity is altered when $\mathrm{CF}_{1}$ is removed from the membrane. Light modulation activates MgATPase activity in thylakoids while DTT stimulates CaATPase activity in isolated $\mathrm{CF}_{1}$ (4). Other treatments that enhance $\mathrm{CF}_{1}$ activity also show a cation specificity: trypsin (CaATPase) (5), solvents (MgATPase) $(6,7)$, or detergents (MgATPase or CaATPase, depending on method of activation) $(8,9)$.

In this report, we show that latent cyanobacterial ATPase activity in Spirulina membrane vesicles and $F_{1}$ is elicited by treatments that stimulate chloroplast activity. We also show that ATP acts both as an inhibitor and as an allosteric effector of CaATPase activity in Spirulina $\mathrm{F}_{1}$. The accompanying paper (13) discusses the purification of the five-subunit reconstitutively active $F_{1}$ ATPase from photosynthetic membranes of Spirulina platensis.

\section{MATERIALS AND METHODS}

Trypsin-activated ATPase activity was assayed routinely in a reaction mixture containing $50 \mathrm{mM}$ Tricine, $\mathrm{pH} \mathrm{8.0,10} \mathrm{mM} \mathrm{CaCl}$, and $5 \mathrm{~mm}$ ATP. Substrate concentrations were varied where indicated. Assays were initiated by the addition of 2-5 $\mu \mathrm{g}$ Spirulina $F_{1}$ or membrane vesicles equivalent to $5-10 \mu \mathrm{g} \mathrm{chl} \mathrm{a.} \mathrm{Lib-}$ erated phosphate was determined spectrophotometrically as the reduced phosphomolybdate complex, according to the method developed by LeBel et al (10), as described by Jagendorf (11). The reaction was terminated after $5 \mathrm{~min}$ at $37^{\circ} \mathrm{C}$ by the addition of $1 \mathrm{ml}$ of color reagent containing $2 \%(\mathrm{w} / \mathrm{v})$ trichloroacetic acid, $2.4 \mathrm{M}$ acetic acid, $0.4 \mathrm{M}$ sodium acetate, $12 \mathrm{mM}$ $\mathrm{CuSO}_{4} \cdot 5 \mathrm{H}_{2} \mathrm{O}, 1 \%(\mathrm{w} / \mathrm{v})$ ammonium molybdate, $1 \%(\mathrm{w} /$ v) $\mathrm{Na}_{2} \mathrm{SO}_{3}, 0.4 \%(\mathrm{w} / \mathrm{v})$ elon, and $1 \% \mathrm{SDS}$. Color development was stopped after $5 \mathrm{~min}$ by the addition of

\footnotetext{
${ }^{2}$ Abbreviations used: $F_{1}$, the hydrophilic portion of the proton-translocating ATPase complex; $\mathrm{CF}_{1}$, chloroplast $F_{1}$; PMS, phenazine methosulfate; chl, chlorophyll; DTT, dithiothreitol; Tricine, $N$-tris(hydroxymethyl)methylglycine; SDS, sodium dodecyl sulfate.
}

$0.1 \mathrm{ml}$ of $34 \%$ sodium citrate (12). Reaction vessels, containing the reaction mixture plus or minus phosphate standards, were incubated alongside the sample assays; in the case of the membrane ATPase assays, an equivalent volume of membranes was added to these tubes after addition of the color reagent. Concentrations of the CaATP metal nucleotide complex were calculated using a dissociation constant of $50 \mu \mathrm{M}$ at $\mathrm{pH} 8.0$ for the complex (W. Frasch, personal communication). The calculations were not corrected for the weak binding of calcium by Tricine.

Trypsin activation was accomplished either by adding trypsin $\left(5 \mathrm{mg} / \mathrm{ml}\right.$ in $\left.1 \mathrm{mM} \mathrm{H}_{2} \mathrm{SO}_{4}\right)$ to the reaction mixture (trypsin:ATPase, 10-20:1 w/w) or by incubating the ATPase or membranes at room temperature with the amounts of trypsin indicated in the appropriate figure, in a solution containing $50 \mathrm{mM}$ Tricine ( $\mathrm{pH} 8.0$ ) and $0.2 \mathrm{mg} / \mathrm{ml}$ ATPase or $0.1 \mathrm{mg} \mathrm{chl}$ $\mathrm{a} / \mathrm{ml}$ membrane vesicles. The digestion was terminated at the specified intervals by a threefold excess of soybean trypsin inhibitor. Controls were treated identically except that trypsin inhibitor was added prior to the trypsin. Methanol-stimulated MgATPase assays contained $25 \mathrm{mM}$ Tricine, $\mathrm{pH} 8.6,2.5 \mathrm{mM} \mathrm{MgCl}_{2}$, $5 \mathrm{mM} \mathrm{ATP}$, and the indicated amount of methanol (v) v). Reactions were initiated by $2-5 \mu \mathrm{g}$ of Spirulina ATPase or membrane vesicles equivalent to $5-10 \mu \mathrm{g}$ chl a. The reaction was terminated after 2 min at $37^{\circ} \mathrm{C}$ as above, and color development was allowed to proceed for $10 \mathrm{~min}$.

The procedure for light activation of membrane MgATPase was that of McCarty and Racker (4). Membranes $(70 \mu \mathrm{g} \mathrm{chl} \mathrm{a} / \mathrm{ml}$ ) were illuminated (approximately $3 \times 10^{6} \mathrm{ergs} \mathrm{cm}^{-2} \mathrm{~s}^{-1}$ ) for $5 \mathrm{~min}$ in a solution containing $50 \mathrm{~mm}$ Tricine, $\mathrm{pH} 8.0,50 \mathrm{mM} \mathrm{NaCl}$, $5 \mathrm{~mm} \mathrm{MgCl} 2,0.1 \mathrm{~mm}$ PMS, and $5 \mathrm{~mm}$ DTT. Aliquots containing $1.4 \mu \mathrm{g} \mathrm{chl} \mathrm{a} \mathrm{were} \mathrm{transferred} \mathrm{to} \mathrm{reaction}$ mixtures containing $50 \mathrm{~mm}$ Tris- $\mathrm{Cl}$, pH 8.0, $5 \mathrm{~mm}$ $\mathrm{MgCl}_{2}$, and $5 \mathrm{mM} \mathrm{ATP}$ and assayed at $37^{\circ} \mathrm{C}$ for $30 \mathrm{~min}$ in the dark. Dilhiothreitul activation of isolated Spirulina $\mathrm{F}_{1}$ followed that of Nalin and MeCarty (3). Spirulina $\mathrm{F}_{1}$ was incubated at $1 \mathrm{mg} / \mathrm{ml}$ in $50 \mathrm{mM}$ Tris$\mathrm{Cl}, \mathrm{pH}$ 8.0, $1 \mathrm{mM}$ ATP, $1 \mathrm{mM}$ EDTA, and $50 \mathrm{mM}$ dithiothreitol at room temperature and aliquots containing $5 \mu \mathrm{g}$ were assayed at 15 -min intervals over a 2 -h period. Spirulina $\mathrm{F}_{\mathrm{l}}$ is maximally stimulated by 15 min incubation with DTT; $\mathrm{CF}_{1}$ activity continues to increase up to $60 \mathrm{~min}(3)$.

Procedures for isolation of photosynthetic membrane vesicles and the coupling factor ATPase of the membranes of S. platensis are detailed in (13).

Protein was estimated by the method of Lowry et al. using bovine serum albumin as the standard (14). Chlorophyll was determined by the procedure of Arnon (15).

\section{RESULTS}

Membrane ATPase. Untreated photosynthetic membrane vesicles from $S$. pla- 
tensis catalyze low levels of ATP hydrolysis, 0.6-2.3 $\mu \mathrm{mol} P_{\mathrm{i}} \mathrm{min}^{-1} \mathrm{mg} \mathrm{chl}^{-1}$ for CaATPase activity, and 1-1.2 $\mu \mathrm{mol} P_{\mathrm{i}} \mathrm{min}^{-1}$ $\mathrm{mg} \mathrm{chl}{ }^{-1}$ for $\mathrm{Mg}$-dependent ATPase activity. CaATPase activity is increased approximately fivefold by trypsin digestion prior to ATPase assay (Fig. 1A), a procedure Vambutas and Racker discovered to be effective in activating chloroplast thylakoid ATPase activity (5). Optimal rates are obtained with short periods of exposure to relatively high concentrations of trypsin. More effective activation occurs when trypsin is added directly to the reaction mixture (Fig. 1B). An 8- to 10-fold increase in CaATPase activity relative to untreated membranes is observed under these conditions. The CaATPase activity of the membranes ranged from 13 to 16 , and averaged $14.5 \mu \mathrm{mol} P_{\mathrm{i}} \mathrm{min}^{-1} \mathrm{mg} \mathrm{chl}^{-1}$. ATPase activity is stimulated 30 to $50 \%$ by trypsin treatment simultaneous with ATPase assay relative to trypsin treatment prior to assay.

The procedure of McCarty and Racker (4) for light activation of chloroplast thylakoids was used to assay light-modulated ATPase activity of Spirulina membrane vesicles. As shown in Table I, a lightactivated, dithiothreitol-dependent $\mathrm{Mg}$ ATPase activity could be demonstrated in Spirulina membrane vesicles. Light activation with DTT stimulates activity about sixfold relative to dark controls without DTT. However, the stimulation is only twofold relative to dark controls with DTT, suggesting that DTT by itself can partially activate the membrane-bound ATPase.

The basal levels of MgATPase in Spirulina membranes under our usual MgATPase assay conditions $\left(2 \mathrm{~min}\right.$ at $\left.37^{\circ} \mathrm{C}\right)$ are 1-1.2 $\mu \mathrm{mol} \quad P_{\mathrm{i}} \mathrm{min}^{-1} \mathrm{mg} \mathrm{chl}^{-1}$. Varying the concentrations of $\mathbf{M g}$ and ATP or altering the ratio of $\mathrm{Mg}$ to ATP did not increase the activity. Methanol has been shown to be a rapid, reproducible, and highly effective stimulator of MgATPase activity in spinach chloroplast thylakoid membranes (7). Methanol proved to be a potent stimulator of Mg-dependent ATPase activity in Spirulina membranes. In contrast to spinach chloroplasts, which are maximally stimulated at $35 \%$ methanol, optimal stimulation of Spirulina membranes occurs when $25 \%$ methanol is included in the reaction mixture (Fig. 2). The specific activity of the membrane MgATPase increases 12- to 15-fold to about $15 \mu \mathrm{mol} P_{\mathrm{i}} \mathrm{min}^{-1} \mathrm{mg} \mathrm{chl}^{-1}$ with methanol stimulation.

Catalytic activity of purified Spirulina ATPase. As detailed in the preceding paper (13), the coupling factor ATPase has been isolated and purified from Spirulina membrane vesicles. While the MgATPase activity of untreated Spirulina $\mathrm{F}_{1}$ is barely de-
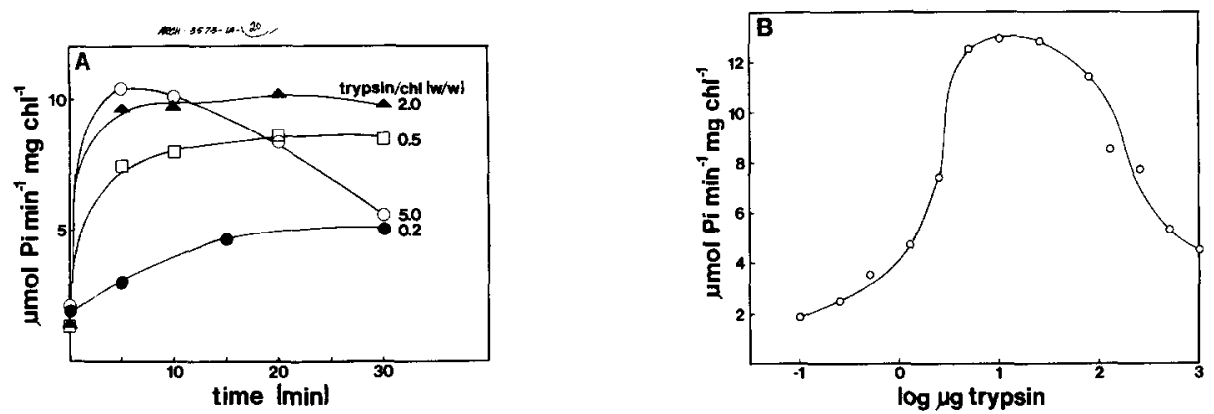

FIg 1. Trypsin activation of Spirulina membrane CaATPase activity. (A) Time course of activation by trypsin digestion prior to ATPase assay. Spirulina membrane vesicles $(0.1 \mathrm{mg} \mathrm{chl} / \mathrm{ml})$ were

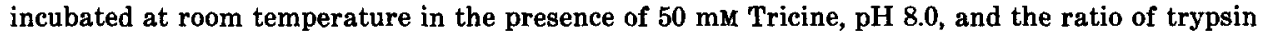
to $\mathrm{chl}$ is indicated. Digestion was terminated at the indicated times by the addition of a threefold excess of soybean trypsin inhibitor. Aliquots of the activation mixture containing $10 \mu \mathrm{g}$ chl were assayed for $5 \mathrm{~min}$ at $37^{\circ} \mathrm{C}$ in a reaction mixture containing $50 \mathrm{mM}$ Tricine, $\mathrm{pH} 8.0,10 \mathrm{mM} \mathrm{CaCl}_{2}$, and $5 \mathrm{~mm}$ ATP. (B) Activation by inclusion of trypsin in the ATPase assay. Spirulina membrane vesicles equivalent to $8 \mu \mathrm{g} \mathrm{chl}$ were assayed as described above except that the indicated amount of trypsin was included in the reaction mixture. The rate without trypsin was $1.6 \mu \mathrm{mol} P_{\mathrm{i}} \mathrm{min}^{-1} \mathrm{chl}^{-1}$. 
TABLE I

Light Activation of Spirulina Membrane ATPase ACTIVITY

\begin{tabular}{cc}
\hline Conditions & $\begin{array}{c}\text { MgATPase activity } \\
\left(\mu \mathrm{mol} P_{\mathrm{i}} \min ^{-1} \mathrm{mg} \mathrm{chl}^{-1}\right)\end{array}$ \\
\hline +DTT, light & $1.7-2.0$ \\
+DTT, dark & $0.8-1.0$ \\
-DTT, light & $0.4-0.6$ \\
-DTT, dark & $0.2-0.4$ \\
\hline
\end{tabular}

Note. Spirulina membranes were kept in the dark or illuminated in a solution containing $50 \mathrm{~mm}$ Tricine, pH 8.0, $50 \mathrm{mM} \mathrm{NaCl}, 5 \mathrm{mM} \mathrm{MgCl}_{2}, 0.1 \mathrm{mM}$ PMS, with or without DTT ( $5 \mathrm{mM}$ ). After $5 \mathrm{~min}$, aliquots were assayed for MgATPase activity in the dark for $30 \mathrm{~min}$ as described under Materials and Methods. The ranges of two independent experiments with two different membrane preparations are given. Each value is the average of duplicate determinations.

tectable, Spirulina $\mathrm{F}_{1}$ catalyzes measurable levels of calcium-dependent hydrolysis, averaging about $4 \mu \mathrm{mol} P_{\mathrm{i}} \mathrm{min}^{-1} \mathrm{mg}$ protein $^{-1}$. Under conditions that increase spinach $\mathrm{CF}_{1}$ activity 8- to 10 -fold, dithiothreitol treatment of $F_{1}$ increases the specific activity (CaATPase) about $40 \%$ to 5.6 $\mu \mathrm{mol} P_{\mathrm{i}} \mathrm{min}^{-1} \mathrm{mg}^{-1}$ (data not shown). That DTT treatment is much more effective with spinach $\mathrm{CF}_{1}$ may be at least partially due to the lower specific activity of untreated $\mathrm{CF}_{1}$, around $1 \mu \mathrm{mol} P_{\mathrm{i}} \mathrm{min}^{-1} \mathrm{mg}^{-1}$. When trypsin treated, as described below, Spirulina $\mathrm{F}_{1}$ CaATPase activity increases to 27-37 $\mu \mathrm{mol} P_{\mathrm{i}} \mathrm{min}^{-1} \mathrm{mg}^{-1}$ which is equal

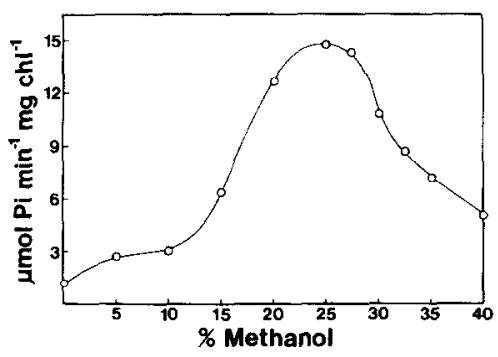

FIG. 2. Methanol stimulation of Spirulina membrane MgATPase activity. Spirulina membrane vesicles equivalent to $8 \mu \mathrm{g} \mathrm{chl}$ were assayed for $2 \mathrm{~min}$ at $37^{\circ} \mathrm{C}$ in a reaction mixture containing $25 \mathrm{~mm}$ Tricine, $\mathrm{pH}$ 8.6, $2.5 \mathrm{mM} \mathrm{MgCl}_{2}, 5 \mathrm{mM} \mathrm{ATP}$, and the indicated amount of methanol $(\mathrm{v} / \mathrm{v})$. to or greater than reported values for spinach $\mathrm{CF}_{1}$, but again the extent of activation is lower with Spirulina $\mathrm{F}_{1}$. Thus, Spirulina $\mathrm{F}_{1}$ behaves catalytically as if it is partially activated, at least in comparison to spinach $\mathrm{CF}_{1}$. Although this could be due to a partial loss of $\epsilon$ subunit (an ATPase inhibitor (16)) content during purification which is not detectable on Coomassiestained polyacrylamide gels, it is more probably an inherent property of the enzyme, since the membrane-bound and soluble enzyme are activated to about the same extent (8- to 10-fold) by trypsin.

Digestion of Spirulina $F_{1}$ by trypsin prior to ATPase assay elicits a five- to sixfold increase in CaATPase activity $(20-25 \mu \mathrm{mol}$ $P_{\mathrm{i}} \min ^{-1} \mathrm{mg}^{-1}$ ); we have shown that optimal trypsin activation requires higher concentrations of trypsin and longer digestion times than are observed with spinach $\mathrm{CF}_{1}$ (17). Higher specific activities, averaging 33.4 $\mu \mathrm{mol} P_{\mathrm{i}} \mathrm{min}^{-1} \mathrm{mg}$ protein ${ }^{-1}$, are observed when trypsin activation and ATPase assays are carried out simultaneously (data not shown). As was found for membrane CaATPase activity, soluble Spirulina $F_{1}$ is stimulated 30 to $50 \%$ by trypsin treatment simultaneous with assay relative to trypsin treatment prior to assay.

The nucleotide and metal specificities of the purified Spirulina coupling factor were

TABLE II

NuCleotide SPECIFICITY of Trypsin-ACtivated Spirulina $F_{1}$

\begin{tabular}{ccc}
\hline & $\begin{array}{c}\text { Specific activity } \\
\left(\mu \text { mol }_{\mathrm{i}} \text { min }^{-1}\right.\end{array}$ & \\
Substrate & mg protein & \\
\hline ATP & \% of control \\
GTP & 23.6 & $100 \%$ \\
ITP & 7.9 & 33.5 \\
CTP & 6.9 & 29.2 \\
TTP & 1.3 & 5.5 \\
UTP & 0 & 0 \\
ADP & 0.4 & 1.7 \\
PP & 0.6 & 2.5 \\
\hline
\end{tabular}

Note. Spirulina $\mathrm{F}_{1}$ was activated for $15 \mathrm{~min}$ at room temperature, as described under Materials and Methods, and assayed for $5 \mathrm{~min}$ at $37^{\circ} \mathrm{C}$ in a reaction mixture containing $50 \mathrm{mM}$ Tricine, $\mathrm{pH} 8.0,10 \mathrm{mM} \mathrm{CaCl}$, and $5 \mathrm{~mm}$ nucleotide. 
determined for the trypsin-activated enzyme. As expected, the preferred nucleotide is ATP, with other purine nucleoside triphosphates producing lower, but significant, levels of hydrolytic activity (Table II). The pyrimidine nucleoside triphosphates, as well as ADP and pyrophosphate, are essentially inactive as substrates. These results are similar to those reported for isolated spinach $\mathrm{CF}_{1}(5)$ and for chloroplast thylakoid ATP synthetic and hydrolytic activities (18). The trypsin-activated enzyme shows a marked preference for calcium over Mg, Mn, or $\mathrm{Zn}$ (Table III) and in this regard is much more metal specific than is spinach $\mathrm{CF}_{1}$ (19).

Although, as noted above, the endogenous MgATPase activity of Spirulina $\mathrm{F}_{1}$ is quite low $\left(0.2-0.3 \mu \mathrm{mol} \mathrm{min} \mathrm{mg}^{-1} \mathrm{mg}^{-1}\right.$ ), very significant MgATPase activity is revealed in the presence of certain organic solvents. Three solvents which were particularly effective in stimulating spinach $\mathrm{CF}_{1} \mathrm{Mg}$ ATPase activity (6) were tested for their effects on Spirulina $\mathrm{F}_{1}$. As shown in Fig. 3 , methanol $(25 \%)$ is the most effective solvent, increasing the specific activity of the Spirulina MgATPase over 50-fold to 18-20 $\mu \mathrm{mol} P_{\mathrm{i}} \min ^{-1} \mathrm{mg}$ protein ${ }^{-1}$. Ethanol $(20 \%)$ raises the specific activity to $5.0 \mu \mathrm{mol} P_{\mathrm{i}}$ $\mathrm{min}^{-1} \mathrm{mg}$ protein ${ }^{-1}$, while acetone completely inhibits activity at all concentrations tested.

\section{TABLE III}

Cation Specificity of Trypsin-Activated Spirulina $\mathrm{F}_{1}$

\begin{tabular}{lccc}
\hline & \multicolumn{3}{c}{$\begin{array}{c}\text { Specific activity } \\
\left(\mu \text { mol } P_{\mathbf{i}}\right.\end{array}$} \\
\multicolumn{1}{c}{ Metal } & $\begin{array}{c}\text { Metal } \\
(\mathrm{mM})\end{array}$ & $\begin{array}{c}\text { min }^{-1} \mathrm{mg} \\
\left.\text { protein }^{-1}\right)\end{array}$ & \% of control \\
\hline Calcium & 20 & 23.0 & $100 \%$ \\
Magnesium & 50 & 3.5 & 15 \\
Manganese & 2 & 1.2 & 5 \\
Zinc & 20 & 0.9 & 4 \\
\hline
\end{tabular}

Note. Spirulina $\mathrm{F}_{1}$ was activated for $15 \mathrm{~min}$ at room temperature, as described under Materials and Methods, and assayed for $5 \mathrm{~min}$ at $37^{\circ} \mathrm{C}$ in a reaction mixture containing $50 \mathrm{~mm}$ Tricine, $\mathrm{pH} 8.0,5 \mathrm{~mm} \mathrm{ATP}$, and varying concentrations (1-50 $\mathrm{mM}$ ) of the metals indicated. The concentration of metal that gave the highest activity is listed.

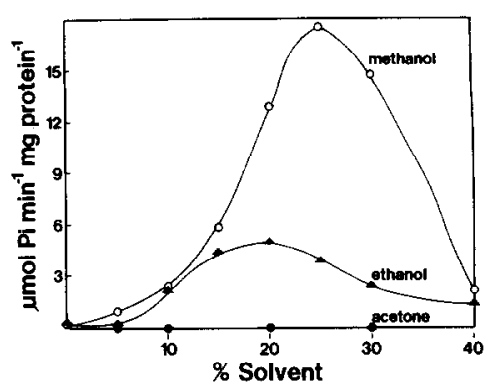

FIG. 3. Effect of solvents on the MgATPase activity of purified Spirulina $\mathrm{F}_{1}$. Spirulina $\mathrm{F}_{1}(5 \mu \mathrm{g})$ was assayed for $2 \mathrm{~min}$ at $37^{\circ} \mathrm{C}$ in a reaction mixture containing $25 \mathrm{mM}$ Tricine, $\mathrm{pH} 8.6,2.5 \mathrm{mM} \mathrm{MgCl}_{2}, 5 \mathrm{mM}$ $\mathrm{ATP}$, and the indicated amount of solvent $(\mathrm{v} / \mathrm{v})$.

Kinetics of the trypsin-activated Spirulina CaATPase. When we examined the $\mathrm{Ca}^{2+}$ dependence of ATPase activity in trypsin-activated Spirulina $\mathrm{F}_{1}$ at a constant ATP concentration ( $5 \mathrm{mM}$ ) we found that the velocity curve is markedly sigmoidal (Fig. 4A). Optimal rates are observed at $10-20 \mathrm{~mm}$ calcium; higher concentrations are only slightly inhibitory. The reciprocal experiment, where the ATP concentration is varied, at a constant calcium concentration of $10 \mathrm{~mm}$, produces a hyperbolic velocity curve except at high concentrations of ATP, which are very inhibitory (Fig. 4B). It has been shown for $\mathrm{CF}_{1}$ that the true substrate for ATP hydrolysis is a divalent cation-nucleotide complex (19). In view of this finding, the sigmoidicity observed when calcium concentration is varied may be explained by the effect of free ATP present in excess of CaATP metal-nucleotide complex. This hypothesis was tested by varying the concentration of the CaATP complex at constant concentrations of free ATP or free calcium. Figure 5 summarizes the results. Concentrations of 1 or $5 \mathrm{~mm}$ free ATP are inhibitory; the inhibition at $5 \mathrm{~mm}$ free ATP is particularly strong. Not only is free ATP an inhibitor; it also is an allosteric effector that yields a sigmoidal velocity plot. This is similar to the effect of ADP on $\mathrm{Mg}$ ATPase activity of $\mathrm{CF}_{1}$ observed by Nelson et al. (20). The Lineweaver-Burk plot of 1 mM free ATP, shown in Fig. 6, is concave, as expected for a velocity plot exhibiting positive cooperativity. The Hill plot of these data also is curved; the slope of the 

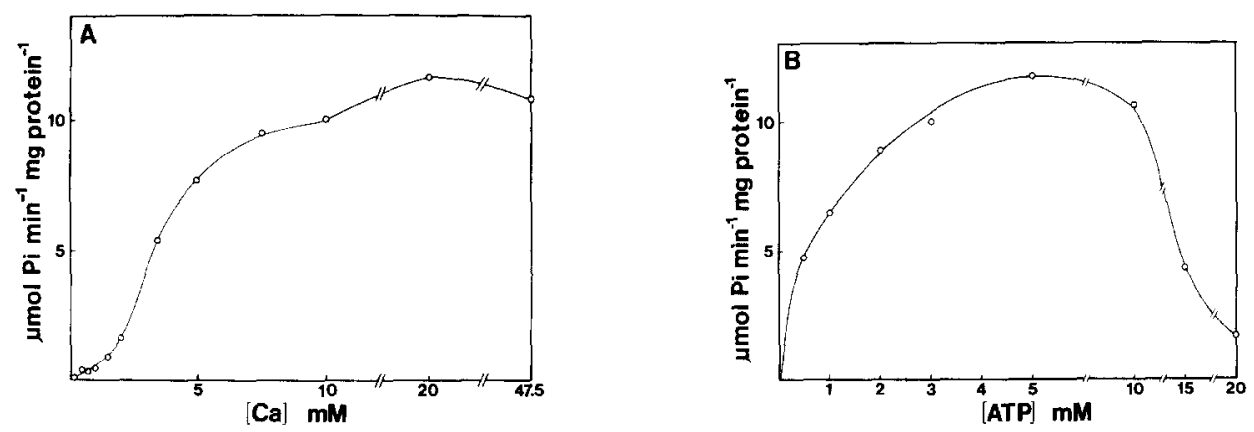

FIG. 4. Effect of varying calcium and ATP concentration on the ATPase activity of trypsin-activated Spirulina $F_{1}$. (A) Effect of varying calcium concentration. Spirulina $F_{1}(0.2 \mathrm{mg} / \mathrm{ml})$ was activated for $15 \mathrm{~min}$ at room temperature in the presence of $50 \mathrm{mM}$ Tricine, $\mathrm{pH} 8.0$, and trypsin $(1 \mathrm{mg} / \mathrm{ml})$. The activation was terminated by a threefold excess of soybean trypsin inhibitor. Aliquots of the activation mixture containing $5 \mu \mathrm{g} \mathrm{F}$ were assayed for $5 \mathrm{~min}$ at $37^{\circ} \mathrm{C}$ in a reaction mixture containing $50 \mathrm{mM}$ Tricine, $\mathrm{pH} 8.0,5 \mathrm{mM}$ ATP, and the indicated concentrations of $\mathrm{CaCl}_{2}$. (B) Effect of varying ATP concentration. Trypsin-activated $\mathrm{F}_{1}$ was assayed in the presence of $50 \mathrm{~mm}$ Tricine, $\mathrm{pH} 8.0,10$ $\mathrm{mM} \mathrm{CaCl}_{2}$, and the indicated concentrations of ATP.

line, i.e., the apparent Hill constant, in the region near $0.5 \mathrm{~V}$, is 1.64 . The average Hill constant of three experiments is $1.72 \pm 0.08$. Other methods for determining the $n_{\text {app }}$ value, as outlined in (21), yielded values of 1.5-1.8. In contrast, at $5 \mathrm{mM}$ free calcium the velocity plot obeys Michaelis-Menten kinetics. The Hill plot for $5 \mathrm{~mm}$ calcium is linear, except at high [CaATP], and the calculated Hill constant is 1.02 (Fig. 7). The $K_{m}$ for CaATP at $5 \mathrm{~mm}$ free calcium, determined from Lineweaver-Burk plots, is $0.43 \pm 0.24(n=3)$ (Fig. 8).

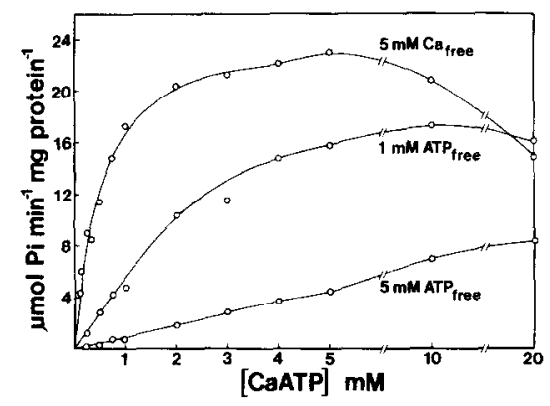

FIG. 5. Effect of varying Ca-ATP metal-nucleotide complex concentration on ATPase activity in trypsinactivated Spirulina $F_{1}$ with different constant concentrations of free calcium or ATP. Trypsin-activated $\mathrm{F}_{1}$ was assayed in the presence of $50 \mathrm{~mm}$ Tricine, $\mathrm{pH}$ 8.0, and the indicated concentrations of Ca-ATP complex with the concentrations of free calcium ( $5 \mathrm{mM}$ ) or free ATP (1 and $5 \mathrm{mM}$ ) held constant.

\section{DISCUSSION}

The ATPase activity of Spirulina $\mathrm{F}_{1}$, whether in the membrane-bound or isolated form, is greater than $80 \%$ latent as defined by the ratio of endogenous activity to the activity observed when activated. The endogenous activity of Spirulina membranes is substantially increased by light modulation in the presence of dithiothreitol, a procedure that has been found in chloroplasts to follow the same apparent

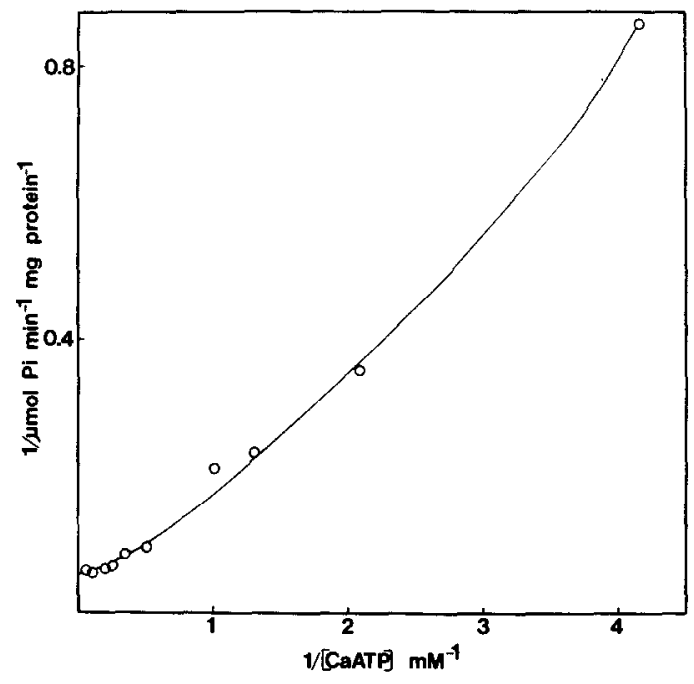

Fig. 6. Plot of $1 / v$ versus $1 /[\mathrm{CaATP}]$ with free [ATP] held constant at $1 \mathrm{mM}$. Conditions were as described in Fig. 5 with the free ATP concentration set at $1 \mathrm{mM}$. 


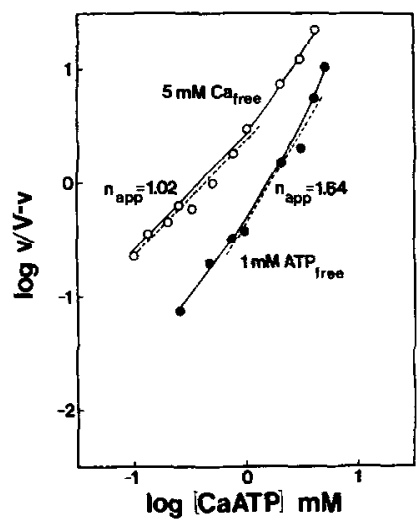

FIG. 7. Hill plot of effect of free calcium and free ATP on CaATPase activity in trypsin-activated Spirulina $F_{1}$. Conditions were as deseribed in Fig. 5 with the free calcium concentration set at $5 \mathrm{~mm}$ and the free ATP concentration set at $1 \mathrm{mM}$. The lines were determined by linear regression using points in the region of $v=0.5 \mathrm{~V}$ ( 8 points in the case of free calcium, 5 points in the case of free ATP).

mechanism as the in vivo activation of chloroplast ATPase activity by illumination of leaves (22) or intact chloroplasts (23, 24). Dithiothreitol also stimulates Spirulina $F_{1}$ activity, though to a lesser extent than is observed with $\mathrm{CF}_{1}$. Whether the lower stimulation is due to suboptimal activation conditions or whether the enzyme undergoes changes upon solubilization that make it less sensitive to dithiothreitol is not known. Spirulina $\mathrm{F}_{1}$ does undergo a shift in metal preference from $\mathbf{M g}$ (light modulation) to $\mathrm{Ca}$ (dithiothreitol) when removed from the membrane just as observed with $\mathrm{CF}_{1}$. Furthermore, the $\gamma$ subunit of Spirulina $F_{1}$ cross-reacts with antibodies to the $\gamma$ subunit of spinach $\mathrm{CF}_{1}(\mathrm{~N}$. Nelson, personal communication). Thus, we believe that Spimulina $F_{1}$ is probably subject to the same light/dark modulation correlated with reduction of a dithiol group in the $\gamma$ subunit that appears to regulate $\mathrm{CF}_{1}$ activity $(2,22-24)$. Other procedures that activate $\mathrm{CF}_{1}$ also stimulate Spirulina $F_{1}$ activity in the same cation-specific manner. While these latter procedures (trypsin, alcohols) are certainly unphysiological, they suggest that key molecular properties relating to catalytic control are shared by the cyanobacterial enzyme and its chloroplast counterpart.
The purified Spirulina ATPase has some interesting kinetic properties. At $5 \mathrm{~mm}$ ATP, a plot of varying calcium concentration against specific activity shows pronounced sigmoidal character. Similar published plots for $\mathrm{CF}_{1}$ and for the Mastigocladus laminosus ATPase, although not discussed in those reports, also appear to be sigmoidal, but to a much lesser degree $(19,25)$. The origin of the sigmoidicity we observe is probably not from cooperative binding of calcium, but rather is due to inhibition by the free ATP present in excess of the metal-nucleotide complex concentration. Evidence for this is seen in Figs. 5,6 , and 8 , where the CaATP complex concentration is varied at constant concentrations of free ATP or free calcium. When excess free ATP is present, the kinetics no longer obey the Michaelis-Menten kinetics that are observed when excess free calcium is present. Thus, binding of substrate (CaATP metal-nucleotide complex) is noncooperative when free ATP is absent, but changes to cooperative binding in the presence of the allosteric effector, free ATP. Free ATP does not appear to be an allosteric effector of spinach $\mathrm{CF}_{1}$ since $1 / v$ versus $1 / S$ plots at constant free ATP are linear (26); instead, ATP is a competitive inhibitor of spinach $\mathrm{CF}_{1}$. The effect of free ATP on the Spirulina ATPase resembles the effect of ADP observed with spinach $\mathrm{CF}_{1}$ (MgATPase) (20), with Chlamydo-

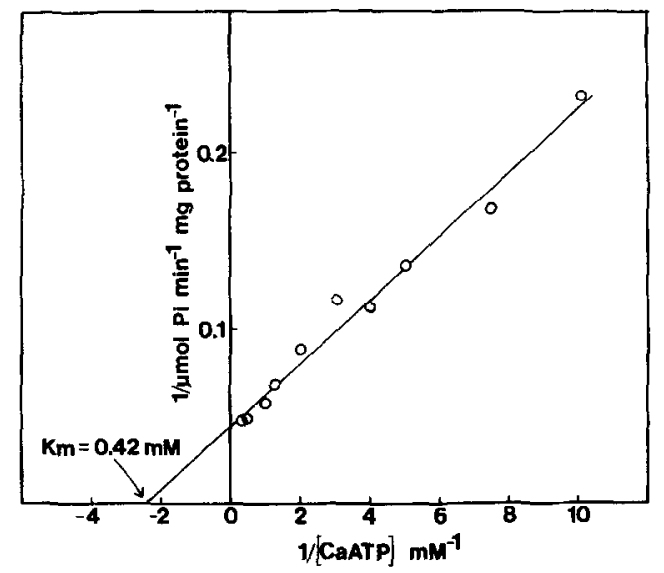

Fig. 8. Plot of $1 / v$ versus $1 /$ [CaATP] with free [Ca] held constant at $5 \mathrm{mM}$. Conditions were as described in Fig. 5 with the free calcium concentration set at $5 \mathrm{~mm}$. 
momas $\mathrm{CF}_{1}$ in the presence of ethanol (27), and with the $M$. laminosus $\mathrm{F}_{1}(28)$.

Regulation of ATPase activity in chloroplasts appears to be very complex [reviewed in (2)]. In addition to the control exerted by proton gradients generated by light-driven electron transport or ATP hydrolysis, regulation of ATPase activity probably involves conformational changes in $\mathrm{CF}_{1}$ correlated with the reduction of a disulfide group in the $\gamma$ subunit. The effects of ADP and certain anions such as bicarbonate and phosphate on the kinetics of $\mathrm{CF}_{1}$ suggest that these small molecules are likely to have a physiological role in controlling ATPase activity. Free ATP, because it is only a weak competitive inhibitor of $\mathrm{CF}_{1}$, is not thought to be a significant factor in ATPase regulation. The latency and activation of ATPase activity in both the membrane-bound and soluble Spirulina $\mathrm{F}_{1}$ suggest that the membrane ATPase activity of Spirulina may be subject to the same regulation found in chloroplasts. Our finding that ATP is both a potent inhibitor and an allosteric effector of soluble Spirulina $\mathrm{F}_{1}$ CaATPase activity, however, would indicate that, unlike the situation with $\mathrm{CF}_{1}$, ATP may be involved in regulating ATPase activity in Spirulina membranes. Since these data were collected using the soluble $F_{1}$, it will be necessary to extend these studies to an examination of the effects of ATP on ATPase activity in Spirulina membranes, especially on the light-activated activity, to determine what role ATP has in controlling the hydrolysis of ATP in vivo.

\section{REFERENCES}

1. Petrack, B., AND Lipmann, F. (1961) in Light and Life (McElroy, W. D., and Glass, B., eds.), pp. 621-630, The Johns Hopkins Press, Baltimore.

2. MCCARTY, R. E., AND CARMELI, C. (1982) in Energy Conversion in Plants and Bacteria (Govindjee, ed.), pp. 647-695, Academic Press, New York.

3. NALIN, C. M., AND MCCARTY, R. E. (1984) J. Biol. Chem. 259, 7275-7280.

4. MCCARTY, R. E., AND RACKeR, E. (1968) J. Biol. Chem. 253, 129-137.
5. Vambutas, V., AND Racker, E. (1965) J. Biol. Chem. 240, 2660-2667.

6. Sakurai, H., Shinohara, K., Hisabori, T., AND SHINOHARA, K. (1981) J. Biochem. 90, 95-102.

7. ANTON, G. E., AND JAGENDORF, A. T. (1983) Biochim. Biophys. Acta 723, 358-365.

8. Pick, U., and BRassilian, S. (1981) in Energy Coupling in Photosynthesis (Selman, B. R., and Selman-Reimer, S., eds.), pp. 251-260, Elsevier/ North-Holland, New York.

9. YU, F., AND McCaRTY, R. E. (1985) Arch. Biochem. Biophys. 238, 61-68.

10. LeBel, D., Poirier, G. G., and Beaudoin, A. R. (1978) Anal. Biochem. 85, 86-89.

11. JAGENDORF, A. T. (1982) in Methods in Chloroplast Molecular Biology (Edelman, M., Hallick, R. B., and Chua, N.-H., eds.), pp. 881-898, Elsevier, Amsterdam.

12. Lanzetta, P. A., Alvarez, L. J., Reinach, P. S., AND Candia, O. A. (1979) Anal Biochem. 100, 95-97.

13. Hicks, D. B., AND YocuM, C. F. (1986) Arch. Biochem. Biophys. 245, 220-229.

14. Lowry, O. H., Rosebrough, N. J., FARR, A. L., AND RaNDaLl, R. J. (1951) J. Biol. Chem. 193, 265-275.

15. Arnon, D. I. (1949) Plant Physiol. 24, 1-15.

16. Nelson, N., Nelson, II., AND Racker, E. (1972) J. Biol. Chem. 247, 7657-7662.

17. Hicks, D. B., AND YocUM, C. F. (1984) in Advances in Photosynthesis Research, Vol. II, pp. 599602, Martinus Nijhoff/Dr. W. Junk, The Hague.

18. Bennun, F., AND Avron, M. (1965) Biochim. Biophys. Acta 109, 117-127.

19. HochmaN, Y., LANIR, A., AND CARMELI, C. (1976) FEBS Lett. 61, 255-259.

20. Nelson, N., NelSON, H., AND RACKER, E. (1972) J. Biol. Chem. 247, 6506-6510.

21. SEGEL, I. H. (1975) Enzyme Kinetics, Wiley, New York.

22. Vallejos, R. H., Arana, J. L., aND Ravizzini, R. A. (1983) J. Biol Chem. 258, 7317-7321.

23. Mills, J. D., Mitchell, P., and SchurmanN, P. (1980) FEBS Lett. 112, 173-177.

24. Ketcham, S. R., Davenport, J. W., Warnke, K., AND MCCARTY, R. E. (1984) J. Biol. Chem. 259, 7286-7293.

25. BINDER, A., AND BACHOFEN, R. (1979) FEBS Lett. $104,66-70$.

26. Hochman, Y., and Carmeli, C. (1981) Biochemistry 20, 6287-6292.

27. KNeusel, R. E., Merchant, S., and Selman, B. R. (1982) Biochim. Biophys. Acta 681, 337344.

28. WOLF, M., BINDER, A., AND BACHOFEN, R. (1981) Eur. J. Biochem. 118, 423-427. 